Liberal Studies in Science at Manchester, did his share of that in 1966, when the department was started. In 1966 there were thirteen students who had originally applied or were already in the traditional science departments. Last year there were ninety-three applicants, some again from the traditional departments, for eighteen places. This year a hundred applications were made direct and the academie standard of those accepted compares well with students in the other science departments. What is more, this summer the other great obstacle to recruitment, namely the fear of potential students that employers will fight shy of people graduating from a general science course, seems to have been disposed of. 'Twenty-seven of the thirtytwo first and second year students took vacation jobs from no less than 171 offers from companies and public corporations and several of them have, on the strength of their summer's work, been offered jobs as soon as they graduate and apparently most of the companies were very enthusiastic about the quality of the students.

Professor Jevons says business is thriving. What is the successful formula? Insisting on high calibre students from the very start (GCE A-level grades of a $\mathrm{B}$ and two Cs including physics and mathematics are the usual requirements) is perhaps the most important factor. But the course which has attracted these students is a judicious blend over three years of economies, history of science, biological and physical sciences, mathematics and science policy, obviously a very different approach to generalist science from that adopted at Stirling. The department is now about to apply to the SRC for funds for a postgraduate course to start next year and to cater for graduates from the conventional science departments. Judging from the SRC's latest policy statement (see page 216), there should be little difficulty in getting the money. But being copied is the best evidence of success, and at Sussex there is talk, at the postgraduate Unit for the Study of Science Policy, of setting up an undergraduate course along the lines of that at Manchester.

Neither the Manchester nor Stirling courses have accepted any arts sixth formers although Manchester is trying to decide how best to do this and at Stirling the only essential requirement is A-level mathematics. The university says it will teach science to any arts applicant with this qualification but, perhaps fortunately, no one has taken up its offer yet. At Bath, however, the one year postgraduate course in the Sociology of Science, directed by Professor Cotgrove, is designed for sociologists although there is a preliminary year's conversion course to introduce scientists and engineers to the ways of sociology. The whole project, however, is on the point of collapse because only two people have enrolled in its first two years. Unless it gets off the ground next year, which must seem unlikely; Professor Cotgrove says the university will have to stop the course or alternatively, if anything comes of current discussions with industry, change it into a course for industrial scientists likely to move into administration.

\section{STUDENT RECRUITMENT Swing Back to Science}

Is the swing in the popularity of British university courses from science to arts and social science courses a continuing trend, or has the attention recently devoted to the problem been effective in arresting the swing? At the beginning of the new academic year, the general opinion seems to be that the number of applicants for science places as a fraction of the total number of applicants is much the same as it was last year, and that at least it is not decreasing as much as might have been feared. There is even some evidence of a swing back to the sciences among school children now entering sixth forms.

The number of places available at universities is determined principally by the amount of money the University Grants Committee (UGC) can be persuaded to part with, and this in turn depends on the demand for places in previous years and on existing long-term plans for expansion. Cuts have forced Exeter University, for instance, to reduce quotas for admissions to science departments by 10 per cent this year. Elsewhere, quotas for admission to science faculties are about the same as last year, and usually they seem to have been filled. Some universities admit that if more science places were available, they might have some difficulty in filling them without lowering standards.

A parameter used as a measure of the relative popularities of various courses is the ratio of the number of applications to the number of available places for various subjects. This is not a particularly meaningful statistic because the number of applications includes all applications, irrespective of their quality, but it does give some indication of general trends. At Sussex University this year the ratio is 21 for arts subjects and 13 for science subjects-ranging from 21 for biochemistry, through psychology, applied sciences, physics, chemistry and biology to 8 for mathematics. Last year, the ratios were $9 \cdot 5$ for science subjects and 21 for arts subjects. The fact that the number of arts applications is not rising as rapidly as was expected may be explained by some degree of pre-selection at schools, where children are warned that the competition for arts places is fierce. At Birmingham, the number of applicants per science place is 11 this year, compared with 12 last year, and for arts places is 19 this year.

Some of the least popular courses at the older universities are the engineering courses-perhaps a result of the increasing intake of students to the newer technological universities. These, however, appear still to have some difficulty in recruitment. Newer courses, such as biochemistry and computer science, seem to be increasingly attractive. In line with current sensitivity about early specialization, combined honours courses, according to Professor D. J. E. Ingram of Keele University, are becoming more and more popular generally.

\section{SALARIES

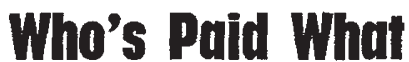

THE five British science institutes have completed salary surveys of their members, and the preliminary results are published as a supplement to Chemistry in Britain. The median salaries by age group for each institute are compared in Table 1. Fellows and associates tend to have better degrees and longer experience than licentiates or graduates. 
Table 1

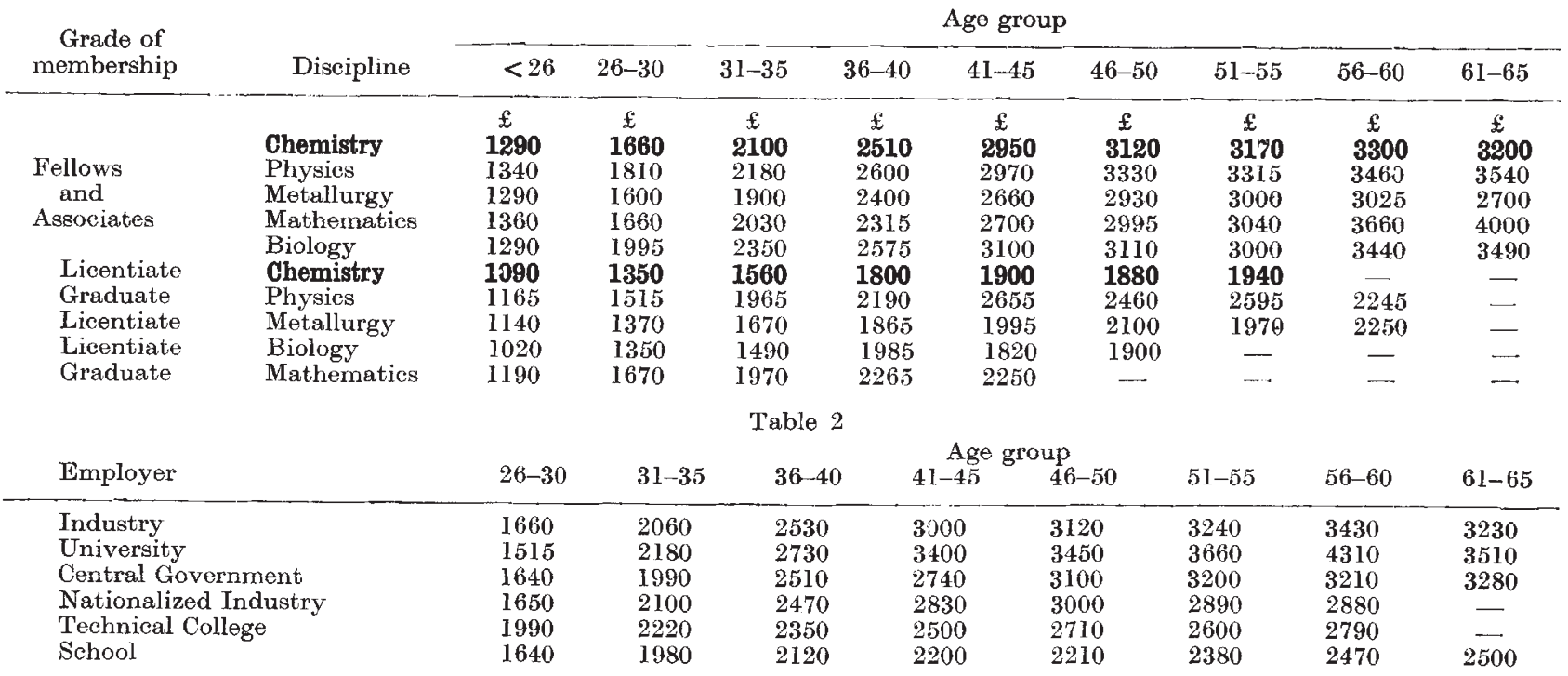

In both grades of membership the physicists and mathematicians appear to climb fastest up the ladder of material success, the mathematicians earning more at earlier ages but being leapfrogged by the physicists in the mid-forties. In the sixties the biologists seem to do better than anyone, the salary of $£ 4,000$ being the median of 42 members. The numbers who responded to the survey include 2,855 biologists and 14,366 chemists (figures for other disciplines are not yet available).

Table 2 gives the median salaries by sector of fellows and associates of the Royal Institute of Chemistry.

A possibly surprising aspect of the survey is that after the age of 30 chemists in industry earn consistently less than their colleagues at universities, which presumably indicates that there is no market shortage. The same is true for physicists, as far as can be judged from the four summary graphs so far issued by the Institute of Physics and the Physical Society. From the age of 30 , associate physicists earn a steady $£ 200$ more in universities than in industry. Graduates of the institute are paid pretty much the same in universities and industry, whereas fellows earn more in universities except between the ages of 44 and 52 when industrial

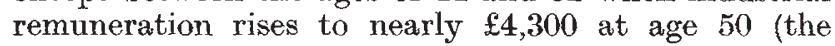

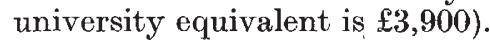

Median salary of chemists has risen by a factor of about 1.8 in all age groups since 1956 , and by $1 \cdot 1$ sirce 1965 . There has been no significant movement of chemists into industry since 1965. The rate for the job, as far as chemists are concerned, does not vary widely between different regions of Great Britain and Ireland.

\section{SPACE DIPLOMACY}

\section{ESRO Up, ELDO Down}

IT has been a mixed week for European science diplomacy.

The most telling event was the news from the ESRO council meeting on October 8-9 that one of the two large TD satellite projects cancelled in April has been rescued. Escalating costs (above the grossly optimistic contractual price of $£ 7$ million) and Italian intransigence over an economy plan to provide one satellite for the price of two had brought about deadlock. ESRO's constitution provides for "special projects" to be undertaken if there is support from two thirds of the member countries. This has been the mechanism adopted for continuing with the stellar TD, intended to be chronologically second and promising to be a very sophisticated and exciting experimental package for the early 1970s. Terms for ESRO special projects are that only those countries taking part pay and ESRO acts as manager. At last week's meeting it turned out that nine out of the ten ESRO countries wanted to take part-Italy is still not interested-so the shares will be very little larger than if it were a full ESRO programme. (The final cost to Britain is expected to be about $\mathfrak{i} 4$ million out of a total bill of about $£ 20$ million.) The degree of agreement represents a triumph for ESRO's new Director-General, Professor H. Bondi, who has personally led the rescue negotiations. There was warm praise from the Science Research Council last week for the way ESRO has handled this affair. This is a symbolic as well as a tangible recovery.

Apart from the TDs (which take their name from their adopted American Thor-Delta launchers), ESRO had no satellite project scheduled beyond this year. The organization was formed to support projects that no individual member could afford on its own. That means satellites either larger or more sophisticated than the British Ariel series on the Reuch Diamant launched payloads. The TDs were both. It remains to be seen if anything can be salvaged from the solar physics TD, due to catch the end of the solar maximum for which several of the experiments, including the British, had been built. There is a well conceived future programme of ESRO satellite launchings ready, but this awaits commitment to a new and increased budget by ESRO countries at the Bonn European Space Conference (ESC) in November.

Also linked with the ESC is the report of the further committee on a long-term European space programme called for by the inconclusive ELDO ministerial meeting on October 1-2 (see Nature, 220, 109; 1968). It is due to report to the ministers the day before the 